\title{
Juventud Rural. Imágenes que rondan al joven en contextos rurales
}

\author{
Ángela Garcés Montoya*
}

Recibido: 30 de septiembre de 2008

Aprobado: 20 de octubre de 2008

\section{Resumen}

Este artículo hace parte de la investigación «Sujeto joven en contexto rural. Una mirada desde las Agrupaciones Juveniles» es una propuesta interinstitucional entre la Caja de Compensación COMFENALCO y la Universidad de Medellín, que compromete a la Sub-Dirección de Educación, Cultura y Bibliotecas y el Grupo de Investigación Discurso, Organización y Política respectivamente. La investigación se realizó en el año 2006 y finalizó cumpliendo los objetivos propuestos en las temáticas: sujeto joven en contexto rural, formas de agrupación juvenil y comunicación alternativa juvenil.

Este proyecto fortalece la línea de investigación en comunicación y Culturas juveniles de la Facultad de Comunicación de la Universidad de Medellín, y permite establecer los mecanismos de gestión que orienten la investigación en juventud en la ciudad de Medellín, como una estrategia para centralizar y brindar información existente sobre juventud y sobre la oferta pública y privada de servicios para la población juvenil. La primera fase del proyecto es de carácter exploratorio, pues permitirá reconocer y visibilizar las condiciones de los /las jóvenes en contextos rurales, siendo pertinente ante la inexistencia de estudios focalizados que consideren las dinámicas, condiciones y subjetividades juveniles en el contexto rural.

Investigadora principal del proyecto «Sujeto joven en contexto rural. Una aproximación a través de las Agrupaciones juveniles». Historiadora, Mg. en Estética; Líder del Grupo Discurso, Organización y Política, especializada en la línea de investigación Comunicación y Culturas juveniles. Investigaciones recientes Culturas juveniles Contemporáneas. Una aproximación antropológica y Mediaciones musicales juveniles, adscritas a la Facultad de Comunicación con el apoyo de la Vicerrectoría de investigación de la Universidad de Medellín. E-mail: agarces@udem.edu.co / culturasjuveniles@gmail.com 


\title{
Palabras clave
}

Juventud rural, organización juvenil, estereotipos juveniles

\section{Rural youth. Stereotypes around the uyoung peasant"}

\begin{abstract}
This essay makes part of the research project called: «Young individual in a rural context. An approach from juvenile groups.» It is an inter-institutional proposal between COMFENALCO and Universidad de Medellin, which involves Education, Culture, and Library Sub-Direction and the Discourse, Organization, and Politics Research Group, respectively. The research will allow formulating and implementing a research line on youth in each institution as a strategy for centralizing and providing existing information about this topic and the public and private offer of services for young population. This first phase of the project is made at an exploratory level as it will allow recognizing and foreseeing conditions of the youngsters in

rural contexts; this research is important because of the lack of focused studies which take into account juvenile dynamics, conditions, and subjectivities in the rural context.
\end{abstract}

\section{Key words}

Rural youth, juvenile organization, stereotypes. 


\section{INTRODUCCIÓN}

Al abordar la Juventud Rural en Medellín como objeto de investigación, se presentan varias limitaciones referidas principalmente a los desarrollos teóricos y conceptuales que reflejan la ausencia de investigaciones que crucen las dimensiones de territorio rural - juventud - ciudadanía. Al menos, como intuición metodológica se reconoce que los /las jóvenes rurales se diferencian de los/las jóvenes urbanos en relación con sus dinámicas cotidianas, sus proyectos de vida e incluso, sus posibilidades de vínculos sociales que los validen como ciudadanos activos, participativos e incluidos. Potenciar y acompañar los estudios sobre juventud rural es clave para llevar a cabo transformaciones necesarias en la capacidad de gestión y visibilidad de los jóvenes rurales y, además, se trata de aportar al ejercicio pleno de la ciudadanía.

Al revisar los estados del arte realizados en Colombia (Escobar, 2003 y 2006) y la región de Antioquia (Zapata y Hoyos, 2004) se constata que los estudios de juventud tienen un fuerte sesgo metropolitano y urbanizante; esa situación, a su vez, se corresponde con las condiciones y orientaciones de la producción de conocimiento en juventud en Colombia. Según el estudio del Estado del arte nacional en investigación en juventud (Escobar, 2006, p. 188-190) elaborado para los últimos 20 años (1983 - 2003) se encuentran como aspectos relevantes las siguientes perspectivas investigativas, que oscilan entre la estigmatización de los jóvenes o el reconocimiento de sujetos productores de cultura, veamos:
- Investigaciones basadas en jóvenes urbanos que asocian al joven con la vulnerabilidad y el riesgo, la búsqueda de identidad y el cambio social. Joven en relación con incompletud, transitoriedad y vulnerabilidad.

- Se reitera la ubicación del joven desde la perspectiva etaria, que se conjuga con la anterior orientación investigativa, que termina por atribuir las problemáticas juveniles a la edad.

- Investigaciones asociadas al reconocimiento de su capacidad de producir cultura; se trata de la noción de un sujeto portador de una cultura específica (subcultura, microculturas, culturas juveniles...). Se reconoce un sujeto joven creador de sentidos y prácticas.

- Recientemente emergen investigaciones orientadas por una noción del joven como sujeto de derechos, bajo el reconocimiento del joven como actor de ciudadanía, en tanto esperanza de transformación social, motor de cambio, agente de protagonismo, etc.

El paso de las representaciones sociales que transitan entre la estigmatización al reconocimiento de las diversidades juveniles nos obligará durante esta investigación a mirar el origen de los estereotipos juveniles en relación con diferentes puntos que involucran las imágenes y representaciones construidas y divulgadas, por una lado, por los medios masivos de comunicación, por otro lado, por los conflictos generacionales, y reforzadas y reproducidas por las industrias del consumo, particularmente difundidas por los discursos publicitarios. En gene- 
ral, las imágenes y representaciones estereotipadas de la juventud responden a su relación como peligro social, como fuerza de cambio y transformación, como consumista compulsivo.

En principio, los medios de comunicación masivos tienen un alto poder en producir y reproducir estereotipos; así la prensa escrita y la televisión masificaron la idea del joven como trasgresor; este estereotipo encarna la figura de un joven y sus comportamientos peligrosos que generan disturbios, al punto de considerarlo un «agente violento por naturaleza»; por ello la pandilla, la banda, la guerrilla..., todas formas de agrupación peligrosas conformadas por alta población juvenil, terminan aludiendo a una relación intrínseca entre joven y violencia. Relación que olvida

... que los jóvenes se asocian a grupos tan diversos como las bandas, milicias, grupos culturales o movimientos cívicos que atestiguan las fuerzas en disputa y los campos de la dinámica social en los cuales se negocian, en situaciones críticas de violencia, las nociones de ciudadanía, identidades culturales, relaciones de clase y poderes territoriales locales. Esas relaciones revelan las paradojas y complejidades que enfrentan quienes viven en medio de la violencia (Riaño, 2006, Introducción).

A su vez, la imagen del joven trasgresor es fortalecida por los conflictos generacionales y culturales que se presentan entre el mundo de los adultos y el de los jóvenes; diferencias generacionales que posicionan imágenes estereotipadas de los/las jóvenes. De un lado, se significa a la juventud como portadora de los valores del cambio social, a la vez que se desliza una negación de las posibilidades de reivindicar y actuar sobre el presente. De otro, el mundo adulto aparece como el espacio legítimo y «verdadero» para el desarrollo personal y la constitución de un proyecto de vida. Este conflicto generacional constituye una evidencia de las luchas de poder que se dan no sólo en torno a la construcción de las identidades sociales, sino por la ocupación de las esferas decisionales. Para Duarte Quapper (2.000), esta concepción entraña cuatro «trampas» que aquí nos interesa referir como síntesis posible de las visiones corrientes que generan estereotipos juveniles, veamos:

1. La universalización como homogeneización: se dice «Son todos iguales», no se elabora ningún tipo de distinciones entre los tipos de jóvenes, vale decir, razas, géneros, clases sociales, estilos - Contraculturas, etc. De esta forma existe sólo una juventud, singular y total al mismo tiempo.

2. Estigmatización del grupo social juventud. Sobre sus prácticas y discursos: se dice «Son un peligro para la sociedad»; la relación que se construye con los/las jóvenes está fundada en desde los prejuicios y los estereotipos. No se logran vínculos humanizadores, sino preimágenes construidas desde las apariencias y miradas preconcebidas que tienden a patologizar a la juventud. 
3. Parcialización de la complejidad social como mecanismo reflexivo: la división etapista del ciclo vital responde a visión instalada con fuerza en los imaginarios sociales en nuestras sociedades latinoamericanas. Se plantea que se es joven o se es adulto (o es infante, o anciano, etc.) negando la posibilidades de convivencias o simultaneidades en la posición que se asume socialmente; así, desde la lógica del mundo adulto los /las jóvenes deben auto constituirse como quienes deben prepararse para afrontar «las futuras generaciones» para la adecuada conducción de las sociedades venideras.

4. La idealización de la juventud como objetivación esencialista: se dice «son los salvadores del mundo». Vale decir, se les endosa una responsabilidad como los portadores de las esperanzas del cambio y la transformación de las diferentes esferas de la sociedad, por el sólo hecho de ser jóvenes. Su carácter intrínseco sería ser críticos e innovadores. Muchas veces se llega a la objetivación mesiánica de plantear que «todo lo juvenil es bueno». Si bien, la mayoría de las veces, los/las jóvenes se encuentran en situación de conflicto social.

Otra representación juvenil estereotipada se refiere a la relación jovenconsumo, posicionada por la publicidad y propaganda; se trata de discursos que divulgan imágenes de jóvenes dispuestos al consumo desmedido; bajo esa lógica promueven modelo de ser joven basado en el consumo compulsivo de mercancías. En tal situación, los jóvenes se convierten en las vitrinas de las mercancías, e imitan las formas que se encuentran asociadas con la riqueza, el hedonismo y la capacidad de poseer cierta cantidad de dinero.

Por último, otra representación que se ha construido en torno al joven se refiere al joven popular vulnerable, se relaciona con la idea de un joven en alto riesgo ante su situación de carencia (educativa, cultural, social, espacial....); esa imagen conduce a la realización de programas en torno a la prevención y atención del joven vulnerable asociado a seguimiento y prevención de la vinculación del joven a las drogas, la violencia, la sexualidad y la reproducción, la muerte y el suicidio.

A partir de esa denominación joven popular vulnerable, aparecen valoraciones que asumen al joven como menor que todavía no alcanza los buenos atributos del adulto, razón por la cuál hay que formar al menor.

Por todo ello no es extraño que las definiciones acerca de la juventud o de la infancia que rondan la escuela, estén todas en función de formar al menor para que llegue a ser adulto, y en el contexto de las sociedades capitalistas de mercado, ser adulto exitoso. Los jóvenes estudiantes son considerados valiosos si en el transcurso de su educación muestran disposición para cumplir con dicho rol (...) De esta manera las y los adultos-docentes son todo aquello que las y los jóvenes estudiantes no son (Duarte, 2002, p. 107). 


\section{LAS JUVENTUDES EN LOS CORREGIMIENTOS}

Al considerar las perspectivas investigativas entre jóvenes vulnerables y jóvenes productores de cultura, es claro que nuestra investigación Sujeto joven en contexto rural. Una aproximación a través de las agrupaciones juveniles reconoce la necesidad de revisar los estereotipos que marcan y fracturan al joven en contextos marginales y, a su vez, reconocer al sujeto productor de cultura en relación con las condiciones sociales y económicas que lo determinan. Por ello, el objetivo principal de la investigación se orienta a «contribuir a la conceptualización del sujeto joven en el contexto rural a través de las formas de agrupación Juvenil presentes en los corregimientos de San Sebastián de Palmitas, San Cristóbal y Altavista».

Ante la ausencia de investigaciones dirigidas a jóvenes en contextos rurales en
Antioquia y particularmente en Medellín, fue necesario considerar el alcance de la investigación como exploratoria y, a su vez, su alcance se restringe a la modalidad descriptiva; además, la investigación dirige su mirada a los/las jóvenes organizados, a través de diversas modalidades: grupos, clubes y organizaciones, pues no se lograba contar con una información cualificada y depurada de la población juvenil en los corregimientos; y la manera más acertada de acceder a ellos, fue a través de sus formas de organización.

Pocas personas en la ciudad de Medellín tienen una imagen clara del territorio rural, de sus dinámicas socioeconómicas y culturales, espaciales y ambientales. Por la proximidad y las relaciones cotidianas con Santa Elena y San Cristóbal, estos corregimientos están en la memoria ciudadana, pero los demás no se perciben como parte de la municipalidad, como son los casos de San Sebastián de Palmitas y Altavista; este último se asocia como parte del barrio de Belén. Ver Mapa: Medellín Rural y urbana

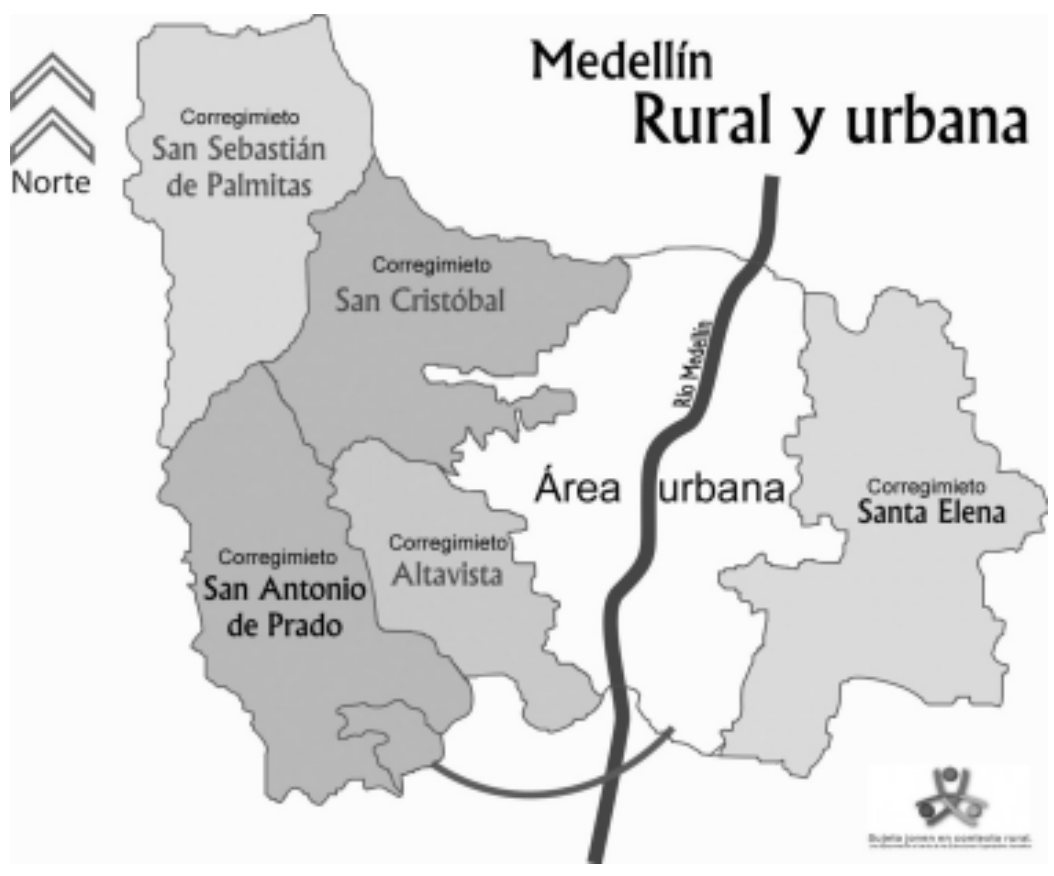


A la ciudad de Medellín se la asume como la totalidad del Municipio, pero prima la imagen de ciudad sobre el entorno rural. Por ejemplo, se desconoce que existe un Medellín rural que es tres veces el tamaño de la ciudad en extensión geográfica. También se desconocen los límites entre la ciudad urbanizada y entorno rural; más aún, poco se valora las dinámicas rurales diferentes a las dinámicas citadinas. Sabemos nombrar a los ciudadanos como sujetos políticos pero no existe una denominación política que incluya a los sujetos en contextos rurales.

Los jóvenes en los corregimientos logran visibilidad a través de sus formas de agrupación; por ello, se convierten en el puente esencial, para avanzar en nuestro proyecto de investigación. Las aproximaciones preliminares a los y las jóvenes organizados en los corregimientos se realizan gracias una base de datos que recoge inicialmente los listados suministrados por Metrojuventud ${ }^{1}$ y luego, esa información se depura con las conversaciones y talleres grupales que reúnen a los líderes de las organizaciones; con ellos y ellas, se logra consolidar la información y contar con 20 agrupaciones juveniles, distribuidas en los corregimientos de estudio, así: Altavista 8 agrupaciones, San Cristóbal 9 agrupaciones, San Sebastián de Palmitas 3 agrupaciones.

El estudio se realiza a través de los / las jóvenes organizados, en tres corregimientos, considerados lugares municipales que aún conservan zonas de producción agrícola y zonas de reserva forestal; aunque por gran contraste, también son espacios de transición entre la ciudad y el campo al sufrir las transformaciones físicas y culturales producidas por las dinámicas de expansión urbana, intensificadas por los procesos de urbanización con sus respectivos desarrollos viales que transforman el paisaje y las dinámicas sociales y productivas.

El acercamiento preliminar a los corregimientos se realiza a través de las agrupaciones juveniles, y los y las líderes de cada agrupación se convierten en guías de recorridos veredales que buscan una interacción entre el equipo de investigación con los ojos de los y las jóvenes. Se logra, primero, un reconocimiento del territorio de cada corregimiento, donde los y las jóvenes nos enseñaban sus espacios cotidianos y sus dinámicas de interacción en sus corregimientos. Luego las entrevistas individuales nos permitieron reconocer sus formas organizativas y aproximarnos a las representaciones de los y las jóvenes en contextos rurales. Gracias a esas técnicas de investigación, es posible contar con este escrito que revisa las representaciones sociales de los y las jóvenes en contextos rurales, centrándose en los estereotipos que giran alrededor del joven campesino.

\section{Juventudes rurales: derivas conceptuales}

Para estudiar las juventudes rurales es necesario hacer referencia a algunas precisiones conceptuales sobre el significado de la juventud en sus contextos, pues ya no se trata de la mirada tradicional de juventud sujeta sólo a la edad y la generación, determinada por la dimensión biológica y su consecuente paso a la adultez, como bien lo menciona Roberto Brito Lemus,

La edad es un criterio que causa confusión, ya que muchos pretenden definir a la juventud delimitándola por rangos de edad, como punto de partida para la in- 
terpretación de la misma. Pero la juventud tiene diversas formas de manifestarse y sólo una de ellas es su duración. Se deben agregar a ellas diversas variables como la clase social, el género, la región y el momento histórico (Brito Lemus: 1996, 27).

Para superar la determinación de la juventud por la variable edad, Brito Lemus resalta que no se debe confundir un criterio demográfico (la edad) con un fenómeno sociológico (la juventud), postulado que ubica la juventud como categoría social y culturalmente definida por los contextos, así su presencia o duración son específicas a cada grupo social donde aparezca. No en vano también afirma Bourdieu: «la juventud y la vejez no están dadas sino que se construyen socialmente en la lucha entre viejos y jóvenes».

Se entiende, además, que existe una juventud oficial que no se corresponde con la juventud entendida como una construcción social; en la perspectiva oficial, la juventud se define en términos etarios, por eso se afirma que se es joven a cierta edad. El concepto juventud ha sido objeto de innumerables estudios, y se corrobora una y otra vez, la dificultad de de encontrar una definición única o universal No obstante, se pueden identificar algunos elementos diferenciadores que permiten nombrar la juventud (Cfr. Garcés, 2003):

- La edad aparece como determinante para comprender la condición de joven. Así, los jóvenes son definidos como un grupo etario comprendido para algunos entre los 15 y los 24 años (ONU) -concepción más aceptada-, y para otros entre los 10 y 19 años (OMS). La edad como marco de referencia etario de un grupo poblacional -en este caso los jó- venes- implica un paso entre la adolescencia y la adultez, ubicando al joven en una etapa transitoria y de «preparación» para ingresar al mundo adulto.

- El cuerpo surge como otro elemento a considerar, en tanto es el portador de signos de consumo (ropa, accesorios, tatuajes, maquillaje, formas de llevar el cabello) y de signos culturales (adscripciones identitarias, gestualidad, comportamientos), donde los distintos elementos utilizados en él y los lugares elegidos para llevarlos poseen una carga y un significado relativos al simbolismo que crean los jóvenes. En esta medida, el cuerpo en el/la joven es un espacio de enunciación permanente, primer plano de interacción social.

- El género es factor constitutivo de las relaciones sociales, marcando notables diferencias entre el joven hombre y la joven mujer en asuntos como la condición biológica, los roles sociales, los espacios de socialización permitidos, entre otros. Hay que reconocer que el cuerpo se ha convertido en el gran paradigma de la juventud, pues se ha desplegado en la publicidad un cuerpo-signo, es decir, un cuerpo joven que se exhibe y se consume. Así el cuerpo joven pone en evidencia que es posible vivir bajo los parámetros del presente, pero el cuerpo también deja ver el paso irreversible del tiempo, pues sobre él opera una ley social determinante que nos recuerda que el cuerpo envejece y ese acto no lo perdona nuestra actual sociedad de consumo.

- La clase social, otro aspecto a tener en cuenta cuando de jóvenes se habla, hace referencia básicamente al estra- 
to económico el cual determina, en el mayor de los casos, el tiempo de prolongación que el joven se toma para asumir las responsabilidades y exigencias propias de la condición adulta, situación que ha sido denominada por Mario Margulis como moratoria social: «La moratoria social alude a que, con la Modernidad, grupos crecientes, que pertenecen por lo común a sectores sociales medios y altos, postergan la edad del matrimonio y de procreación y durante un período cada vez más prolongado, tienen la oportunidad de estudiar y de avanzar en su capacitación (...) Este concepto adhiere implícitamente a ciertos límites vinculados con la condición de juventud: esta etapa transcurriría entre el final de los cambios corporales que acaecen en la adolescencia y la plena integración a la vida social (...) y varía, sin duda entre los diferentes sectores sociales» (Margullis, 1998, p. 5).

La juventud será definida como un momento de tránsito marcado por el ingreso a la juventud y su consecuente superación. Se trata de límites arbitrarios establecidos por instituciones y gobiernos para legislar la población juvenil, mientras en la perspectiva socio-cultural, se entiende al joven como constructor de su propia identidad, fuertemente diferenciada de los mecanismos de poder tradicionales y de los estilos juveniles dispuestos al consumo cultural, representados por la lógica del mercado capitalista globalizado (Garcés, 2005).

Avanzando en la discusión, emerge la noción de moratoria social, que nos ha permitido pensar la juventud como construcción socio-cultural, al considerar la noción de sujeto en relación con sus contextos, situación que obliga a revisar la noción de moratoria psicosocial desarrollada por Eric Erikson, entendida como período intermedio entre la adolescencia y la adultez, siendo un período eminentemente juvenil, aceptado socialmente y donde el individuo ensaya el futuro rol en la sociedad a través de la experimentación de funciones, sin la responsabilidad de asumir ninguna (Erikson, 1971).

Esa noción preliminar de moratoria psicosocial será ampliada por Mario Margullis al diferenciar moratoria social y moratoria vital; entre una y otra hay que considerar el transito etario y, a su vez, la validación social de la condición de juventud. Según Mario Margullis se entiende por moratoria social el tiempo intermedio en el cual los jóvenes, especialmente aquellos de clases media y alta, aplazan compromisos como el matrimonio y procesos como el tener hijos para aumentar sus conocimientos, teniendo más tiempo para el estudio y la capacitación. Esta actitud social se ha venido dando como consecuencia de la Modernidad, ya que ésta cada vez exige más de los jóvenes, pues se ven obligados a sobrevivir en un mundo de competencias para las que se necesita la mejor preparación posible en lo referente a la educación (Margullis, 1998).

Para contextualizar la noción de moratoria social, el investigador Edgar Arias Orozco (Arias, 2004) nos dice que puede ser entendida como temporalidad sociocultural que supone al joven en un momento de preparación para la productividad o, en otras palabras, como sujeto prefuncional al sistema productivo, también con un tiempo destinado al ocio, a la lúdica y a la preparación académica. Sin embargo, la precariedad económica y sus repercusiones, primero en las oportunidades para la preparación 
intelectual y la experimentación de actividades y procesos proclives al desarrollo autónomo del cuerpo, la sensibilidad y el pensamiento, y segundo en la capacidad de otorgar creativa e inteligentemente sentidos y experiencias a su tiempo de juventud hacen que la moratoria social sea vivida de manera diferente según los jóvenes, sus prácticas y contextos.

De tal manera que encontramos unos jóvenes con responsabilidades laborales, económicas y familiares propias de una condición de adultos, con la necesidad de trabajar para aliviar sus dificultades materiales; en tanto otros, sobre todo de sectores medios y altos, tienen resueltas las necesidades básicas y pueden disponer del tiempo de juventud para la preparación intelectual, la recreación, el deporte o el ocio. Sin embargo, el mejor uso de la moratoria social dependerá también de las capacidades que tengan los jóvenes para dotar de significados y expresión su tiempo y lugar particulares, para crear y desarrollar su pensamiento crítico y libre.

Esa disyuntiva genera la pregunta: ¿existe la juventud rural? Y un joven responde «Aquí hay muchos jóvenes, pero no hay juventud». Esa frase sintetiza las condiciones socio-culturales de los jóvenes en contextos rurales, donde las diversas limitaciones (económicas, educativas, recreativas, etc.) nos recuerdan que «pese a estar en un rango de edad determinado, conocido como joven, ello no significa, necesariamente, que se estén viviendo experiencias usualmente identificadas y difundidas como deseables para esa edad»(Osorio, 2005).

Por ello, en la noción de moratoria social y moratoria vital encontramos limitaciones serias para caracterizar a los jóvenes de con- textos rurales, pues si bien esas moratorias posicionan imágenes y significados frecuentes que vinculan al joven con la diversión, el disfrute y la alegría, en los contextos rurales es más frecuente encontrar jóvenes rodeados de múltiples carencias que no les permiten vivir la juventud. Así lo reafirma la investigadora Flor Edilma Osorio

Las y los jóvenes en el campo son valorados fundamentalmente como mano de obra, pero son invisibilizados como actores sociales capaces de comprender, opinar y participar. Las reducidas ofertas de servicios se hacen en tanto productores potenciales, dejando de lado las otras dimensiones fundamentales, como sujetos sociales y políticos. La invisibilidad se traduce también en la homogeneización, que oculta la diversidad de problemáticas, potencialidades, sueños y expectativas.

Esas diversas moratorias hay que ubicarlas en los contextos urbanos y rurales, allí se constata que la juventud urbanopopular, al igual que la juventud rural tienen moratorias mínimas ante la temprana incorporación al trabajo, o la incapacidad del Estado y la sociedad para ofrecer oportunidades de bienestar y tiempo libre para los y las jóvenes. Se reitera desde la perspectiva socio-cultural que no es posible es naturalizar la juventud.

Al pensar las especificidades de la juventud rural, intentamos integrar las problemáticas en relación con la perspectiva de género y el enfoque territorial, que nos obliga a pensar que

la juventud se define por las condiciones de participación en la sociedad; la existencia o ausencia de oportunidades para los/las jóvenes 
definen la manera en que desempeñan roles, así como sus posibilidades de adquirir, reforzar o ampliar, habilidades básicas para la inserción laboral y el desenvolvimiento en el contexto cultural, social y político (Romero, 2003, p. 8).

\section{Representaciones sociales de la juventud rural}

Parece que, al indagar por la juventud rural nos enfrentamos a varias representaciones sociales que es necesario revisar, para lograr visibilizar la condición de juventud presente en los contextos rurales, intención metodológica que orienta la investigación «Sujeto joven en contexto rural. Una aproximación a través de las agrupaciones juveniles». Consideramos entonces

la emergencia de la(s) juventud(es) rural(es) como actor social y sujeto identitario, que no sólo ha renovado la vieja tensión entre la sociología, la antropología de la juventud y las ciencias sociales rurales con respecto a este segmento cultural (...) sino que obliga a pensar si existe una juventud rural como entidad objetiva, como grupo social, o sólo se trata de una categoría analítica (González, 1997).

El artículo del investigador Yanko González Cangas invita a considerar los conceptos de juventudes rurales o juventud rural de manera inclusiva, pues no se trata de relacionar esos conceptos sólo a las juventudes campesinas; ese cuidado teórico y metodológico busca menguar el estereotipo social que lleva a pensar que todo joven rural está determinado por su entorno y por ello su destino es ser campesino.
Es indudable que en nuestros imaginarios urbano/rurales hay una serie de prejuicios culturales y estereotipos que alimentan las representaciones sociales sobre los/las jóvenes rurales. Esos estereotipos llevan la marca y el peso de las representaciones sociales, pues ellas juegan un papel importante a la hora de «concebir y construir la realidad juvenil rural», pues como lo enuncia Pierre (Mannoni, 2001)

Las representaciones sociales tienen tres características: son dinámicas, estructurantes y perseverantes. Las representaciones sociales son procesos cognitivos y emotivos, productores de sentido, así como de realidades simbólicas y dinámicas, y actúan como esquemas organizadores de la realidad, y aseguran la permanencia y la congruencia de lo que es creído.

Al revisar la función simbólica de las representaciones sociales, se nos permite pensar que los estereotipos que rondan al joven campesino lo representan como si fuera una foto fija, sin dinámica histórica ni sociológica. Por ello es necesario revisar las imágenes culturales del joven rural en relación con las representaciones estereotipadas que producen una amnesia histórica y social, al NO dejar ver las diversas formas de ser joven en contextos rurales. Sólo al lograr un proceso de reconocimiento y visibilización de las condiciones de vida de los jóvenes en sus contextos es posible revisar las falsas generalizaciones y sobre todo, las poco apropiadas definiciones de juventud que llevan el peso de los estereotipos, que se desarrollan a continuación.

\section{(La juventud rural no existe»}

El peso de la imagen del joven campesino es tan amplio que hay dificultades para per- 
cibir las juventudes rurales como actores sociales, por ello, se piensa que «la juventud rural no existe»; esa imagen se sustenta en la condición de moratoria negativa entendida como la negación o no presencia de la moratoria social en los jóvenes rurales, ante la inexistencia de espacios propiamente juveniles, como territorios juveniles, tiempos de ocio juvenil, consumo juvenil, etc. De suyo el «joven rural se define como carente de oferta educativa, lúdica, recreativa, cultural entre otras, esa situación revela una «vivencia forzada de la juventud» (Amtmann, 1986). En los contextos rurales encontramos que los /las jóvenes sufren las consecuencias de la exclusión y la marginación y, por tanto, su moratoria social y vital se pierde, se estrecha o la viven de manera deficiente, y hay jóvenes que no trascienden su moratoria social a prácticas de creación y construcción de pensamiento a razón de sus autolimitaciones o su maleabilidad por las lógicas culturales dominantes.

En los corregimientos estudiados se confirma la existencia de la moratoria carenciada. Así, en el primer encuentro juvenil realizado en mayo de 2006, para reunir a los líderes de las agrupaciones juveniles de los tres corregimientos, se logró reflexionar sobre los imaginarios y las condiciones de vida de los jóvenes en sus contextos rurales, ahondando en la comparación entre jóvenes urbanos y jóvenes rurales. Frente a la pregunta: ¿Existen diferencias entre el joven rural y el joven urbano? se logró desvelar la siguiente situación:

\section{Cuadro: Representaciones jóvenes urbanos / jóvenes rurales*}

\begin{tabular}{|l|l|}
\hline \multicolumn{1}{|c|}{ Joven Rural } & \multicolumn{1}{|c|}{ Joven urbano } \\
\hline $\begin{array}{l}\text { Piensa en el bienestar socia } \\
\text { Tienen sentido de pertenencia por su } \\
\text { entornos y por lo que hacen }\end{array}$ & Piensa en su futuro personal \\
\hline $\begin{array}{l}\text { Tiene muchas carencias / menos oportunidades } \\
\text { / mentalidad de limitaciones / tiene más necesi- } \\
\text { dades y dificultades en educación, recreación / } \\
\text { vive por debajo del mundo urbano / Tienen ma- } \\
\text { yores dificultades }\end{array}$ & $\begin{array}{l}\text { Cuenta con más oportunidades: posibilidades de } \\
\text { estudio, universidad, más oportunidades de tra- } \\
\text { bajo / más apoyo }\end{array}$ \\
\hline Campesino y trabajador & $\begin{array}{l}\text { Materialista, predominan los intereses } \\
\text { materiales }\end{array}$ \\
\hline \multicolumn{2}{|c|}{ Consenso de los jóvenes rurales } \\
\hline $\begin{array}{l}\text { Los valores y actuación son diferentes, la forma de vivir también ha sido diferente, la cultura ha sido } \\
\text { diferente / nos diferencian nuestras costumbres y manera de expresarnos / el modo de pensar de todo lo } \\
\text { que nos rodea y apropiarnos de ellas / diferente la forma de ver la vida y forma de pensar }\end{array}$ \\
\hline Son seres distintos, piensan de distinta forma \\
\hline No cuentan con las mismas oportunidades para desarrollar el proyecto de vida \\
\hline El rural tiene más dificultad de ingresos \\
\hline
\end{tabular}

* Síntesis de Encuentro Juvenil de Agrupaciones Juveniles. Mayo 6 de 2006. Reúne a 30 jóvenes líderes de los corregimientos Altavista, San Cristóbal, San Sebastián de Palmitas 
Si revisamos las representaciones sociales de la población campesina en relación con la juventud, se aprecia como «normal» que los y las jóvenes transiten rápido de la niñez a adultez, pues el imaginario social condiciona para que todo hijo(a) cumpla con la promesa de asegurar la continuidad de la producción campesina. Las carencias propias de zonas rurales afectan la vivencia de juventud; por ello, es pertinente la noción de «jóvenes carenciados presentada por Jhon Durston (1997), que alude a los y las jóvenes campesinos que no gozan del bienestar y el estatus de los jóvenes urbanos en relación con el tiempo libre, la educación, los territorios juveniles. Pero, es necesario aclarar que No se pueden relacionar esas carencias sólo con la juventud; en principio, no son exclusivas de la etapa juvenil y, además, se presentan más bien en relación con otras causas como pobreza, aislamiento territorial, violencia, discriminación, entre otras.

Los jóvenes carenciados se enfrentan entonces a un «deber social» propio de zonas campesinas que se refuerza por el papel central de la familia como institución que regula los procesos de socialización y las condiciones de vida cotidiana de los y las jóvenes. Bajo esas condiciones sociales los y las jóvenes sienten que viven en un «mundo muy cerrado», pues cuentan con pocas posibilidades de espacios de jóvenes para jóvenes.

Ese peso social y cultural de la familia y de las industrias culturales, se refuerza con las prácticas y las dinámicas culturales en la vida cotidiana orientadas por las relaciones familiares, reproducen el estereotipo: la juventud rural no existe. Mientras los y las jóvenes mantengan una relación interdependiente entre jóvenes / adultos, regida por la asimetría y la determinación de la vida adulta, será común sentir que su vida es normalita y no goza de espacios, prácticas y dinámicas propias y diferenciadas de los adultos.

La familia juega un papel muy importante en la proyección e interacción de los/las jóvenes en contextos rurales. Quizás se deba a la falta de espacios-tiempo propiamente juveniles, que no les permite a los jóvenes rurales gozar de una condición de juventud. Es común encontrar en las conversaciones con los jóvenes organizados en grupos juveniles, que su aliciente inicial para agruparse es no tanto proyectarse en la comunidad, como

agruparse, básicamente, para aprovechar el tiempo libre, el ocio, y a través una organización, lograr en el uso adecuado del tiempo libre combatir los malos vicios, y a la vez estar haciendo algo que realmente nos gusta, eso es lo que nos llama la atención (Entrevista a joven de San Cristóbal. 2005).

\section{Espacio-tiempo de la juventud rural}

En las entrevistas realizadas a jóvenes habitantes de los corregimientos de Medellín, ellos y ellas reconocen que su vida transita entre la familia y la escuela, se trata de espacios que mantienen una relación asimétrica entre joven y adulto, basada en el control y la proyección de la vida juvenil a partir de las expectativas familiares. Ante esa situación las agrupaciones juveniles ofrecen un «espacio-tiempo de liberación» del mundo adulto; pareciera que en las agrupaciones los y las jóvenes logran ver sus propias búsquedas y sentir que la vida se orien- 
ta por opciones y decisiones propias, y gracias a sus propias iniciativa ser reconocidos en su entorno social. Así lo enuncian algunas jóvenes:

Yamile Guerra (Grupo Juvenil Pioneros): El grupo surgió al mirar que los jóvenes de la vereda en su tiempo libre no tenían nada que hacer, no tenían posibilidades de recrearse e invertir el tiempo en algo útil (...) Los jóvenes salen de estudiar y para la casa, un fin de semana no tienen nada que hacer (...) Así el objetivo de reunirnos, aparte de pasarla rico, es hacer cosas nuevas, cosas que nos sacan de la rutina en que vivimos y también prestar apoyo y servicio a la comunidad (...) Esa iniciativa es de nosotros, pura idea de nosotros mismos, sin esa iniciativa no hubiera surgido nada.

Ana Cristina (Grupo Jóvenes con Futuro): Vimos la necesidad de crear un grupo para empezar a utilizar bien el tiempo libre, porque eran las mujeres en la casa viendo televisión, los hombres jugando fútbol (...) El proyecto de vida de nosotros es lograr que la gente de Medellín nos conozca, que a pesar de que esta es una vereda lejana de la cabecera del corregimiento de San Sebastián de Palmitas, sepan que nosotros somos jóvenes luchadores, mostrar que aquí hay honradez y liderazgo.

Diana Carolina (Grupo Vértigo Juvenil): (La motivación para agruparnos es para buscar una forma de ocupar un poquito el tiempo y comprometernos con algo, ya que no hay nada más que hacer (...) buscamos primero proyectarnos a la comunidad y demostrarnos a nosotros y a la demás gente que los jóvenes nos podemos organizar y podemos aportarle a la sociedad en cuanto desarrollo cultural que en el corregimiento es muy pobre; la idea es que nos conozcan fuera del corregimiento (San Sebastián de Palmitas), que se vea que nosotros hicimos eso no sólo para la gente del corregimiento, y para los jóvenes, sino para toda clase de personas y de todos los lugares».

Como vemos en esos testimonios de las jóvenes agrupadas, ellas reconocen que las agrupaciones juveniles les permiten a los y las jóvenes crear un espacio-tiempo de jóvenes para jóvenes. La agrupación se va configurando como territorio juvenil, considerado un espacio simbólico donde es posible no sólo «pasarla rico» o contar con un «lugar de encuentro», para convertirse en un espacio que rompe la rutina del corregimiento y permite superar la monotonía familia-escuela. La agrupación se va convirtiendo en un espacio-tiempo alternativo para los jóvenes «hacer cosas nuevas»y lograr «iniciativas propias»; así, ellos comienzan a reconfigurar las relaciones con los adultos, pues a través de las decisiones y acciones grupales los jóvenes «no dependen de los adultos». Ellos y ellas, quieren espacios propios logrados a través de sus agrupaciones; con ellas es posible proyectar su vida e incidir en su entorno, pues como concluye Yamile al hablar del grupo: «lo que nos mantiene unidos es el amor que todos los jóvenes sentimos por nuestro corregimientos y por nuestro trabajo comunitario». 
Las formas de agrupación juvenil también fortalecen las identidades de forma diferenciada, tanto en las relaciones generacionales, como en las relaciones de género; pues el protagonismo que logran ellos y ellas les va reafirmando su liderazgo y puliendo la pasividad individual; esas transformaciones identitarias se logran con el desarrollo de varias expresiones y dinámicas que se nombran como propias, como lo enuncia la joven Diana Carolina Muñoz:

Pertenecer a un grupo nos permite integrarnos entre nosotros, así compartimos experiencias y cambiamos de ambiente; eso también nos permite buscar oportunidades, capacitaciones y proyectos (...). Al comienzo agruparse no es fácil, pero luego aprendimos a escucharnos, ya sabemos entendernos y con ello desarrollamos pensamiento crítico, y medir las decisiones a tomar. En fin, aprendemos a estar en sociedad, no ser seres solos y saber que también necesitamos de la otra persona y de la opinión de los demás.

Este testimonio nos permite afirmar que los espacios-tiempo de jóvenes para jóvenes existen y se fortalecen no sólo por su trabajo comunitario y la proyección social que logran en sus acciones, sino también por el fortalecimiento de condición de juventud; además, hay que resaltar que los y las jóvenes no quieren agruparse en las formas tradiciones de organización, como juntas de acción comunitaria o juntas de acción local, pues se trata de espacios organizativos controlados por los adultos, bajo formas de poder jerárquica, donde prima la competencia y el protagonismo individual.

Por ello, en las agrupaciones juveniles encontramos que los y las jóvenes no quieren seguir bajo la figura de la representación tradicional dirigida por el mundo adulto, con sus formas «amañadas de clientelismo». Esa situación se corrobora en la experiencia vivida por los agrupaciones juveniles en la reciente participación de «presupuesto participativo» organizada por la Alcaldía de Medellín, para orientar la inversión comunitaria de manera consultiva. En esa experiencia, quedó claro que las organizaciones tradicionales y las agrupaciones juveniles tienen una perspectiva muy distinta de desarrollo local y forma de privilegiar la inversión. Como se expresó en el grupo focal de agrupaciones juveniles con énfasis en medios alternativos de comunicación:

Es claro que los y las jóvenes cuestionan una visión de desarrollo centrada en el equipamiento urbano, visión que olvida que la ruralidad puede ser un espacio territorial con sus condiciones ambientales, sociales y culturales propias, y por tanto, su única vía de desarrollo no es «parecerse a la ciudad».

Es importante resaltar que las agrupaciones juveniles viven un conflicto social y cultural cifrado en las relaciones asimétricas adulto / joven, basadas en la representación, mientras los procesos organizativos enuncian que los y las jóvenes rurales merecen un reconocimiento y diferenciación de los adultos, donde su gestión, acción y liderazgo sea visto en su particularidad. Así lo expresa un joven: 
En los grupos juveniles, logramos mostrar otra óptica de lo que solo los jóvenes, de lo que podemos hacer, así les toca reconocer que siendo simplemente jóvenes no necesitamos del adulto, ni que otros nos lideren. Nuestra Corporación está conformada netamente por jóvenes, el mayor tiene 22 años, entonces agruparnos significa mostrar qué podemos hacer los jóvenes, las capacidades que tenemos y la oferta cultural; la agrupación también es un espacio interno que nos ofrece otros espacios, dándole al joven ofertas de educación y de escenarios propios) (Foronda, 2005, p. 10).

\section{"Joven: productor campesino"}

Las representaciones sociales que rondan la juventud campesina no hacen otra cosa que sobregeneralizar al joven rural y olvidar los posibles matices identitarios relacionados con las dinámicas complejas de la nueva ruralidad. Ese estereotipo relaciona directamente juventud rural a campesino, y con ello se produce la invisibilidad del joven en ese contexto; no es extraño que

... entre algunos investigadores de juventud, la invisibilidad sea prácticamente total, al punto de que se preguntan: ¿Existe la juventud rural en América Latina? Por supuesto, se entiende el porqué de la pregunta, si se constata que a los 15 años un joven o una joven rural es jefe de hogar, casado y con hijos, y no estudia sino que trabaja para sobrevivir; por ello, parece legítimo suponer que su juventud terminó antes de comenzar (Durston, 1997).
Las representaciones de los jóvenes campesinos difícilmente permiten imaginarlos por fuera de la producción agrícola y pecuaria; si bien, es común encontrarlos vinculados a esas labores, es necesario reconocer que también pueden convivir en ese medio y tener otras labores productivas que no están marcadas por la vinculación y dependencia territorial con la producción campesina.

Según González, en Latinoamérica, la relación juventud rural y producción campesina orientó las investigaciones producidas hasta la década del 1960, desatendiendo la diversidad de actores y dinámicas sociales de los /las jóvenes en su medio rural. Hasta esa década

... la mayoría de los estudios se centraban bien en el campesino o en la familia, como unidad básica de producción y reproducción económica. Sólo a principios de la década de los 70 se comienza a indagar tímidamente en la realidad juvenil rural, se emprenden investigaciones de carácter sociodemográficas y estructurales, preocupadas exclusivamente por los fenómenos migratorios y expectativas de los «objetos», centrados en la incidencia de estos actores en el desarrollo. Claramente pasaban por alto la adscripción identitaria generacional dando por hecho que la «juventud» en el mundo rural no existe, apoyados en los criterios biológicos, como la edad y su residencia espacial (González, 2005, p. 154).

En los 90 sobresale la labor del IICA (Instituto Iberoramericano de Cooperación 
para la Agricultura), quien a través de RELAJUR (Red Latinoamericana de Juventudes Rurales) ha levantado diversas acciones y estudios, referidos en su mayoría a programas de fomento y desarrollo de organizaciones juveniles en el mundo rural. Ser habitante del campo parece contener implícito el peso de «campesino», imagen que ignora los múltiples híbridos culturales, producto no sólo de los medios de comunicación, sino también de las interacciones continuas entre campo y ciudad. Los jóvenes entrevistados reconocen que han nacido en espacios rurales, pero se reafirman en un momento de crisis generacional, pues no quieren, y además se alejan cada vez más, de su destino: ser agricultores. Como lo enuncia Ana Cristina Granda, joven de 17 años, habitante de zona veredal:

De todas maneras nacimos acá (en el campo), de todas maneras seguimos siendo de Palmitas (corregimiento) y tenemos nuestro acento campesino, pero no queremos que el futuro de nosotros sea trabajar la tierra, queremos empezar a administrar las mismas tierras, y no solamente coger el azadón: queremos empezar a administrar las matas de lulo, las granadillas... y no sólo cosechar (Entrevista a joven de San Sebastián de Palmitas, 2005).

Esa afirmación nos obliga a pensar en una renovada imagen de campesino, pues no se trata sólo de un «productor de bienes de pan coger», esa producción destinada al autoabastecimiento familiar; como lo ilustra otra joven, se reafirma la situación y posición de los jóvenes rurales, al afirmar: «podríamos seguir siendo campesinos pero con mejores oportunidades) (Entrevista a joven de San Cristóbal. 2005).

Retomando la perspectiva de género, nos encontramos con la imagen de la mujer rural trabajadora cifrada en el excesivo trabajo, pues su tiempo se reparte entre las labores domésticas y las agrícolas. Además, implica una tercera labor, pues nos encontramos con adolescentes vinculadas a los procesos educativos formales, pero ese rol no las libera de los compromisos familiares, pues según reporta Sonia Zapata «los padres no aceptan que una mujer de campo no quiera y no le guste trabajar la huerta, como dicen ellas: a una la esclavizan con la huerta, con el invernadero' produciéndose en innumerables ocasiones que no se les autorice a realizar otro tipo de trabajo» (Durston, 1997).

\section{«Inmigración juvenil»}

Otra representación social que ronda a las juventudes rurales se refiere a la inmigración juvenil del campo a la ciudad, pues ante las carencias ya mencionadas, parece inevitable que los y las jóvenes migren a la ciudad en busca de educación, trabajo, salud, diversión. Como lo enuncia Martine Driven:

Se sabe (por estudios de caso y encuestas) que un número sustancial de jóvenes rurales no ve su futuro en actividades agrícolas debido a los bajos ingresos, altos riesgos, largas horas de trabajo a la intemperie y porque permite menor independencia del jefe del hogar. Otra razón es la imagen negativa que suscita el trabajador del campo en el 
resto de la sociedad. Otra razón todavía es que muchos jóvenes tienen mayor escolarización y las ocupaciones no agrícolas por lo general retribuyen mejor a esta mayor escolarización que las agrícolas. Por otro lado, se sabe también que mucos jóvenes, entre ellos trabajadores, técnicos y profesionales tanto de formación agrícola como no agrícola, no encuentran trabajo acorde a su especialización y pretensiones salariales en el área rural y, por lo tanto, viven allí frustrados o resignados 0 , finalmente, migran (Driven. 2003, p. 12).

La migración del campo a la ciudad encuentra su fundamento en las precarias condiciones económicas, sociales y culturales que sufren los jóvenes en sus contextos rurales, referidas de manera particular a la baja oferta de empleo y esparcimiento; pero también encuentra su explicación en una variable interdependiente de gran peso referida a la oferta educativa. La educación en contextos rurales tiene serios problemas de calidad, cobertura y continuidad.

El peso de las representaciones de progreso y desarrollo cifradas en la ciudad, y reproducidas por el sistema educativo, aumentan la imagen estereotipada del «joven campesino», al punto que los y las jóvenes consideran inevitable la migración hacia la ciudad, para poder superar «supuestamente» las condiciones desfavorables y quizá insuperables del y la joven en contextos rurales. Por lo expuesto, el «proyecto de vida» de ellos y ellas se visualiza en la ciudad y borra el campo como horizonte de vida y de futuro.
En las entrevistas realizadas a los y las jóvenes de las agrupaciones juveniles de los corregimientos, se confirman las dificultades existentes para terminar sus estudios de bachillerato.

Las dificultades iniciales se relacionan con la falta de establecimientos educativos; si bien, a nivel veredal se cuenta con escuelas que cubren la formación básica primaria, los corregimientos sólo cuentan con un establecimiento de secundaria ubicado en la cabecera del corregimiento, obligando a los jóvenes a largas jornadas de desplazamiento. Pero, a su vez, el nivel de deserción es alto, pues si en promedio inician su ciclo de bachillerato 100 estudiantes, de ellos, solo se gradúan 40 o 50 estudiantes cada año; y a su vez sólo acceden a educación superior uno o dos jóvenes, y las limitaciones para continuar estudio son económicas, pues los jóvenes rápido se vinculan a trabajos informales, buscando algún ingreso económico para favorecer las condiciones familiares (Entrevista a joven de Altavista, 2005).

La falta de ofertas y espacios educativos con calidad y cobertura obliga a los y las jóvenes a migrar a la ciudad. Martine Driven abre varias preguntas que es necesario tener presentes en el estudio de jóvenes y migración; en principio no sabemos cuántos jóvenes migran actualmente, tampoco sabemos cuántos trabajan en ocupaciones rurales no agrícolas, y menos aún, sabemos cuántos preferirían trabajar en agricultura. Una opción para el estudio 
bachiller y profesional es la universidad virtual, pero las ofertas aún son pocas, y no logran cubrir la amplia demanda existente en los corregimientos.

Otro aspecto delicado en la consideración de la migración juvenil a la ciudad se refiere a la variable género, pues las condiciones de migración para ellos y ellas son distintas, y esa diferencia está marcada por los imaginarios masculinos y femeninos atribuidos a cada género y que pesan más en los contextos rurales. Quizás la migración de las jóvenes responda a la necesidad de liberarse del yugo masculino, pues en el campo:

La masculinización tiene mucho que ver con el fuerte sesgo hacia los hombres y la distribución de las tareas, del poder y del reconocimiento social masculino dentro de las instituciones rurales (pareja, familia, grupos sociales, organizaciones productivas, gremios, etc.), espacios que perfilan una perspectiva de futuro a los jóvenes pero muy poca a las jóvenes. Aunque, para las muchachas rurales, en las últimas décadas la educación formal y la emigración abrieron una alternativa a la vida de la mujer campesina (Driven, 2003, p. 3).

Pero lamentablemente la mujer para migrar encuentra un obstáculo mayor cercano y pesado, su propia familia, pues el hogar le reitera que debe permanecer en casa, que no debe andar sola en la noche por la calle, y sobre todo que evite acompañarse siempre de hombres... así, la visión familiar afirma que calle, noche, hombres parecen ser un combinado peligroso para mujer.

\section{NOTAS}

1 Metrojuventud es la Subsecretaría del Municipio de Medellín encargada de coordinar el desarrollo de la Política Pública de Juventud, responsable de incidir en las distintas instancias públicas y privadas para garantizar el cumplimiento de los derechos de los y las jóvenes, la constitución de la juventud como actor estratégico del desarrollo municipal y el mejoramiento de su calidad de vida. Ver: www.metrojuventud.gov.co Unificar una sola secuencia a lo largo del texto

\section{REFERENCIAS BIBLIOGRÁFICAS}

Arias Orozco, Edgar. Generación posible. Prácticas Culturales y Expresiones Juveniles. En: www.medellin.gov.co /cij/addocumentos/ documentos/documentos/ Convivamos.doc (consultado 15 octubre - 2006)

Amtmann, C. y Gonzáles J. (1986) «ntegración social de jóvenes rurales». En: Estudios Sociales. No. 47 (trimestre) Santiago de Chile: Ed. Corporación Promoción Universitaria. 
Brito Lemus, Roberto. (1996). «Hacia una sociología de la juventud». En: Revista Jóvenes. Año 1. No. 1. México (julio - septiembre). pp. $24-33$.

Durston, Jhon. (1997). «uventud rural en Brasil y México. Reduciendo la invisibilidad» Ponencia presentada al XX Congreso de la Asociación Latinoaméricana de Sociología -ALAS. Sao Paulo.

Driven, Martine. (2003). «Algunos datos y reflexiones al rejuvenecimiento de la población en los territorios rurales». En: RED LATINOAMERICANA DE JUVENTUDES RURALES. Juventud Rural en el Cono Sur. Estado de las investigaciones y los desafíos futuros. Compilación del Seminario Internacional Virtual: Juventud Rural en el Cono Sur. Relajar - IICA, 14 y 20 de 2003.

Escobar, Manuel Roberto e alter. Estado del arte del conocimiento producido sobre jóvenes 1985 - 2003. (2004). Bogotá: DIUC - Universidad Central, Programa presidencia Colombia Joven, GTZ, UNICEP. http//www.colombiajoven.gov.co/SIUJ.

Espindola, Daniel. Presentación a: «uventud Rural en el Cono Sur. Estado de las investigaciones y los desafíos futuros». Compilación del Seminario Internacional Virtual: Juventud Rural en el Cono Sur. Relajar - IICA, 14 y 20 de abril de 2003.

Garcés Montoya, A. (2005.) Nos-otros los jóvenes. Polisemias de las culturas y los territorios musicales en Medellín. Medellín: Sello Editorial Universidad de Medellín.

Garcés Montoya, A. (Editora). (2006). Pensar la Comunicación. Reflexiones y avances en investigación. Medellín: Sello Editorial Universidad de Medellín.

González Cangas, Y. (2005). «uventud rural. Trayectorias teóricas y dilemas identitarios». En: Revista Nueva Antropología. Vol. XIX. No. 63. pp. 153 - 175.

Mannoni, Pierre. (2003) Les représentations sociales. París, Presses Universitaieres de France, 2001. Citado por: RODRIGO ALSINA, Miquel. «Representación de la inmigración: el poder en la construcción de la alteridad». En: Revista Signo y Pensamiento. No. 43. Facultad de Comunicación, Universidad Pontificia Bolivariana, julio - diciembre.

Alsina, Miquel. (2003). «Representación de la inmigración: el poder en la construcción de la alteridad». En: Revista Signo y Pensamiento. No. 43. Facultad de Comunicación, Universidad Pontificia Bolivariana, julio - diciembre.

Romero, Juan. Introducción a. «uventud Rural en el Cono Sur. Estado de las investigaciones y los desafíos futuros». Compilación del Seminario Internacional Virtual: Juventud Rural en el Cono Sur. Relajar - IICA, 14 y 20 de abril de 2003.

Vegas Guerrero, Carmen y otros. «Estados, proceso y desafios de las juventudes rurales en Perú». En: www.pj.gob.pe/temporales/juventudes rurales/Default.htm. Consultada el 16 de mayo de 2008. 